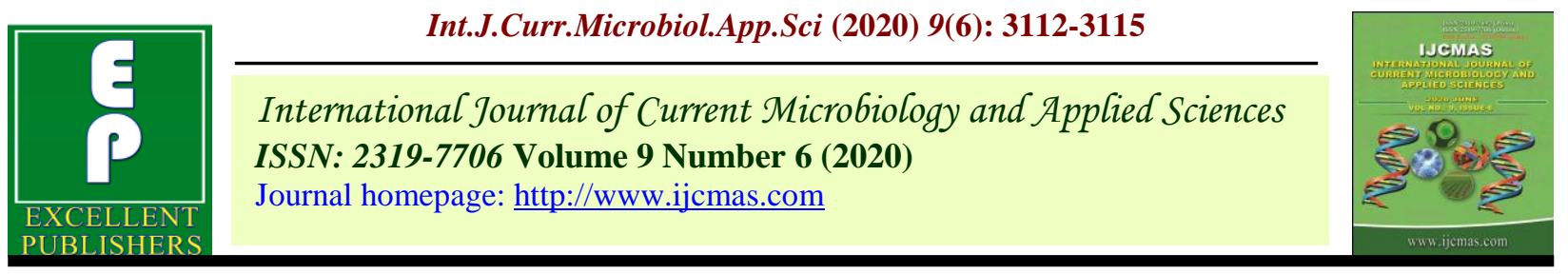

Case Study

https://doi.org/10.20546/ijcmas.2020.906.372

\title{
An Unusual Presentation of Lymphatic Filariasis in Non-Endemic Country
}

\author{
Hasan Khalaf*, Noor Alhalabi and Basim Almothafar \\ Al Adala quarter, Alnajaf city 00964, Iraq \\ *Corresponding author
}

\begin{tabular}{|l|}
\hline Keyw ord s \\
Microfilaria, \\
FNAC, cytology \\
\hline Article Info \\
\hline $\begin{array}{l}\text { Accepted: } \\
\text { 21 May } 2020 \\
\text { Available Online: } \\
\text { 10 June } 2020\end{array}$ \\
\hline
\end{tabular}

\section{A B S T R A C T}

Wuchereria bancrofti is a human parasitic worm (Filariworm) that is the major cause of lymphatic filariasis. It is one of the three parasitic worms, together with Brugia malayi and B. timori, that infect the lymphatic system to cause lymphatic filariasis. These filarial worms are spread by a variety of mosquito vector species. The usual form presentation of the disease is as hydrocele, acute or chronic lymphatic obstruction or subclinical microfilaremia. Finding of Wuchereria bancrofti in a cytological smear from upper arm abscess is a rare presentation. We discuss here a case of 19years old female with recurrent abscesses and small ulcers in the arm and forearm. FNAC smears Cytology revealed sheathed microfilaria without any nucleus in the tail end confirming the species as Wuchereria bancrofti. The case is highlighted the rare presentation of WB and the role FNAC smear cytology in diagnosing filariasis.

\section{Introduction}

Filariasis is a worldwide health problem in the tropical and subtropical regions of Africa, Asia, the Western Pacific, and parts of America. Out of 893 million people in 49 countries at risk of infection, 120 million people are infected presenting commonly with lymphatic filariasis. (1). In developing countries, filariasis is still a wide public health problem but It is extremely rare in Iraq. There are eight species of filarial parasite can cause infection to the human being.
Wuchereria bancrofti, Brugia malayi and Brugia timori cause Lymphatic filariasis, while cutaneous lesions are caused mainly by Onchocerca volvulus and Loa loa (2).

W. bancrofti has a worldwide distribution and it accounts for $90 \%$ of detected filariasis cases, which is more prominent than Brugia malayi and Brugia timori. Clinical manifestations include lymphangitis, lymphadenitis, lymphatic obstruction, hydrocele and elephantiasis (3). The conventional diagnostic procedure is for the 
demonstration of microfilaria in peripheral blood smears.(4) Even though incidence is high, it is unusual to detect microfilaria in fine-needle aspiration cytology (FNAC) smears. Incidental detection of microfilariae in fine-needle aspirates of different types of lesions has been reported widely and most of the cases were clinically unsuspected.(5)

Here, we are presenting a case with recurrent left upper limb abscesses, ulcers, and swelling that diagnosed by FNAC.

\section{Case report}

A 19-year-old female patient presented to AlSadr Teaching Hospital in Iraq, a General surgery clinic with a history of 9 months of the left arm and forearm swelling, with skin changes. She complained of recurrent small forearm abscesses that incised and drained few times and treated initially with Coamoxyclav. Then, she was seen by a dermatologist and treated with Rifampicin as a suspicion for TB for three months. She presented to the General surgical clinic with a recurrent abscess in the medial side of the forearm and small ulcers. These ulcers are associated with yellowish discharge with no specific odor. The arm was not painful, and she was complaining of mid-night itching mainly around her ulcers. She had no past medical history. On examination, the left arm is with swelling to double size the other one. There was a small abscess $(2 * 2 \mathrm{~cm})$ is located superficially on the medial aspect of the left elbow, mildly tender, not hot nor tender. The ulcers are 5 in numbers of variable size but the largest one is $1.5 \mathrm{~cm}$ in diameter, they are round, superficial, firm, with sloped edges. They are not tender and attached to the subcutaneous tissue. Mild signs of bacterial infection were noted. Well defined enlarged axillary lymph nodes were noted. Her blood tests were normal apart from ESR was around 40.
The abscess content was aspirated by a wide bore needle this time and send for cytology. Cytological examination of Giemsa-stained smear showed several microfilaria in the background of degenerated inflammatory cells that comprised of eosinophils, neutrophils, histiocytes, and lymphocytes. The microfilaria had typical features of the presence of hyaline sheath, cephalic space, and tail end devoid of nuclei. So, these are Wuchereria bancrofti.

The patient was treated with diethylcarbamazine citrate (DEC) $(6 \mathrm{mg} / \mathrm{kg})$ and albendazole (400 mg) with dramatic response. All her ulcers are healed with minimal scars. Follow up in 4 weeks, 4 months showed good results and no recurrence.

Filariasis is seen in tropical and subtropical countries and is a vector-borne disease due to infection by eight species filarial worms that infect and spread through the human lymphatic system(2). It is extremely rare in Iraq. People who live or stay for long periods in tropical and sub-tropical endemic areas are more at risk of infection in these areas like India. Wuchereria bancrofti accounts for about $90 \%$ of the cases. (6) Clinical presentations may be variable and in most cases are diagnosed incidentally. Symptomatic patients may present with lymphoedema of different areas of the body or repeated attacks of acute lymphangioadenitis or dermatolymphangio-adenitis. Lymph vessels are the habitat of the adult worms and the first change in lymphatic filariasis is usually dilation of these vessels which in turn leads to lymphatic obstruction. The manifestations of these changes lead to lower limb lymphoedema, chyluria, hydrocoele, lymphadenovarix, and tropical pulmonary eosinophilia in advance cases. (7). Filariasis is usually diagnosed by identifying microfilariae on Giemsa stained, thin and 
thick blood film smears, using the "gold standard" known as the finger prick test. Serologic techniques provide an alternative to microscopic detection of microfilariae for the diagnosis of lymphatic filariasis.

Patients with active filarial infection typically have elevated levels of antifilarial IgG4 in the blood.(8). Fine needle aspiration cytology (FNAC) is not used commonly for diagnosis. However, the detection of microfilaria has been reported on cytology smears.(5) In our case, the patient is from a non-endemic country and had a typical presentation. The presenting symptoms were mainly recurrent abscesses and small ulcers of the left arm. Although the diagnosis using FNAC is not common even in endemic regions, detection of microfilaria was made by examination of the smear cytology. Therefore, careful history taking, clinical examination, and good clinical knowledge will help in diagnosing similar cases (Fig. 1 and 2).

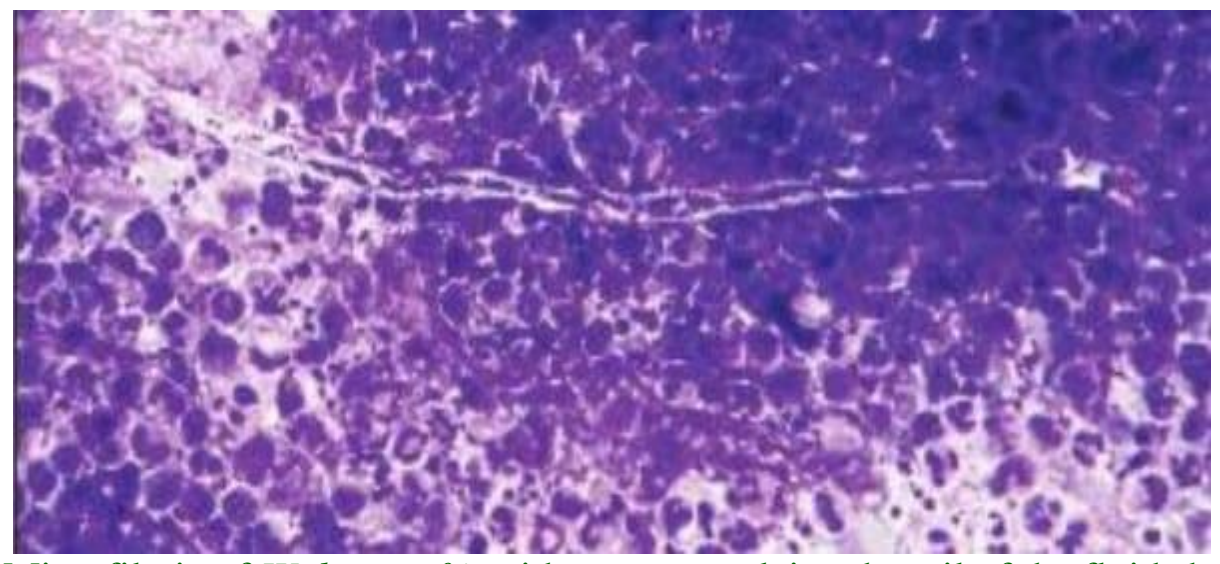

Fig.1 Microfilaria of W. bancrofti. without any nuclei at the tail of the fluid shows of W. bancrofti, Giemsa stain
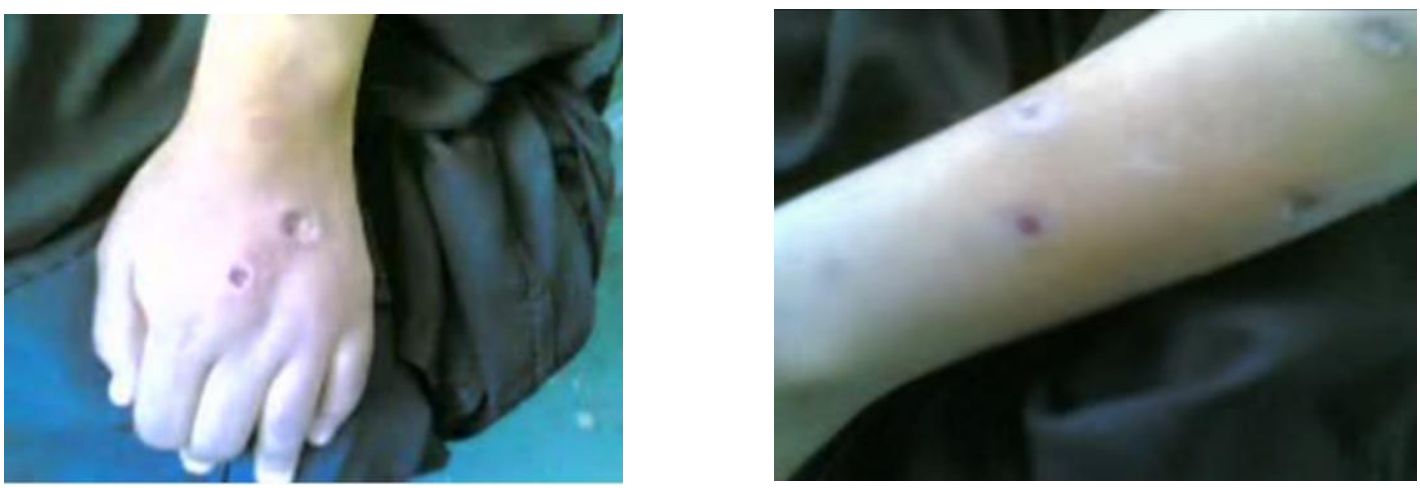

Fig.2 Patient forearm and hand showing the ulcers

Although Filariasis is extremely rare in The Gulf region, physicians should be aware of such cases especially with atypical presentation. This case summarizes a typical presentation of Lymphatic filariasis in the non-endemic country and the aim of FNAC to reach the diagnosis.

\section{References}

1. WHO, fact sheets, Filariasis 2018 https://www.who.int/news-room/factsheets/detail/lymphatic-filariasis

2. Park K. Epidemiology of communicable diseases. In: Park K, 
editor. Park's text book of preventive and social medicine. 24rd ed. New Delhi: Bhanot publishers; 2017. p. 270

3. Lau M, Tauchi P, Kim M, Liu F, Namiki T. Filarisis of the breast in a pregnant women diagnosed by fineneedle aspiration cytology: a case report. Infect Dis Obstet Gynecol. 1995; 3: 245-7.

4. Basu A, Sistla SC, Verma SK, Jagdish S. Lymphadenovarix in the axilla - an unusual presentation of filariasis. Filaria J. 2006; 30: 5-9. http://www.filariajournal.com/ content $/ 5 / 1 / 9$

5. Al Bozom I, Koshy SM, Mahdi H, Abdullah MF, Bedair EM.
Retroperitoneal filariasis diagnosed by fine needle aspiration: A case report. Acta Cytol. 2010; 54(3): 325-327.

6. Utzinger, J., Bergquist, R., Olveda, R. and Zhou, XN. Important helminth infections in Southeast Asia diversity, potential for control and prospects for elimination. Adv Parasitol; 72C: (2010). 1-30.

7. Kumar and Clark clinical medicine $8^{\text {th }}$ edition 2012, British library, Publisher, Parveen Kumar, Michael Clark, editors, $\mathrm{p} 153$

8. Centers for Disease Control and Prevention: Lymphatic Filariasis. CDC. 2020

\section{How to cite this article:}

Hasan Khalaf, Noor Alhalabi and Basim Almothafar. 2020. An Unusual Presentation of Lymphatic Filariasis in Non-Endemic Country. Int.J.Curr.Microbiol.App.Sci. 9(06): 31123115. doi: https://doi.org/10.20546/ijcmas.2020.906.372 